\title{
Ultrabiomicroscopic-Histopathologic Correlations in Individuals with Autosomal Dominant Congenital Microcoria: Three-Generation Family Report
}

\author{
Arturo Ramirez-Miranda ${ }^{a}$ Juan M. Paulin-Huerta ${ }^{a}$ \\ Eduardo Chavez-Mondragón ${ }^{a} \quad$ Gilberto Islas-de la Vegab \\ Abelardo Rodriguez-Reyes ${ }^{c}$
}

${ }^{a}$ Anterior Segment Department, and b Ocular Imaging Department, Instituto de Oftalmología Fundación Conde de Valenciana, and 'Ophthalmic Pathology Service, APEC, Hospital 'Dr. Luis

Sanchez Bulnes', Mexico City, Mexico

\section{Key Words}

Microcoria · Ultrasound biomicroscopy · Iris · Histopathology

\begin{abstract}
Background: Congenital microcoria (CMC) is due to a maldevelopment of the dilator pupillae muscle of the iris, with a pupil diameter of less than $2 \mathrm{~mm}$. It is associated with juvenile open angle glaucoma and myopia. We report on a three-generation MexicanMestizo family with CMC. The eldest member's iris biopsy proved muscle anomalies. Further, we analyzed novel ultrasound biomicroscopy findings in the family members who did not require surgery.
\end{abstract}

Patients and Methods: A 62-year-old woman, her 41-year-old son and her 9-year-old grandson affected with microcoria since birth, documented by clinical examination and ultrasound biomicroscopy. The eldest member underwent phacoemulsification, and a biopsy of the iris and the anterior capsule of the lens was taken.

Results: Ultrasound biomicroscopy confirmed the CMC diagnosis showing iris thinning and a pupil diameter of less than $2 \mathrm{~mm}$. Histopathology of the iris showed a significant reduction of smooth muscle cells, but no alterations of the anterior lens capsule.

Discussion: Although CMC is a rare disorder, which is due to a maldevelopment of the dilator pupillae muscle of the iris, it could be associated with juvenile open angle glaucoma and myopia; therefore, precise diagnosis is required. Ultrasound biomicroscopy could be a great option to confirm the disorder. 


\section{Introduction}

Autosomal dominant congenital microcoria (CMC), also called congenital miosis, is a rare disorder due to a maldevelopment of the dilator pupillae muscle of the iris, and it is characterized by a pupil diameter of less than $2 \mathrm{~mm}$, iris hypopigmentation and transillumination defects. Affected individuals have no response to topically administered mydriatic drugs. CMC is associated with juvenile open angle glaucoma and myopia [1]. Linkage analysis in French and Indian pedigrees indicated that the responsible gene is located in the chromosomal locus 13q31-q32 [2]. We report on 3 affected individuals from a non-consanguineous Mexican-Mestizo family with CMC with a similar degree of severity. The eldest family member required cataract surgery; therefore, we observed the histopathology of the iris and excised lens capsule, suggesting that the lens is not affected in this anterior segment anomaly.

\section{Patients and Methods}

A 62-year-old woman (patient 1) presented with blurred vision and nyctalopia since childhood, noticing a bilateral, painless, gradual deterioration in her vision over the preceding 5 years. She reported no ophthalmic history and was systemically normal. Her best-corrected visual acuity was 20/200 in both eyes. Bilateral pupillary diameter of less than $2 \mathrm{~mm}$ in scotopic illumination, a hyperpigmented peripupillary area and transillumination defects of peripheral iris were identified, with no response to topically administrated mydriatic drugs (ig. 1a, b), as well as bilateral dense nuclear cataract. The intraocular pressure was $16 \mathrm{~mm} \mathrm{Hg}$ in both eyes. The fundus was difficult to evaluate due to the small pupil. Examination of the patient's son and grandson aged 41 years and 9 years, respectively (patients 2 and 3 ), revealed the same iris configurations without cataracts (fig. $2 \mathrm{a}, \mathrm{b}$ ). The best-corrected visual acuity was $20 / 20$ in both patients. In patient 2 , the refractive error was $-7.00 \mathrm{sph}$ in both eyes; in patient 3 , it was plano $-0.75 \times 175$ in the right eye and plano $-0.50 \times 5$ in the left eye. They also had normal intraocular pressures (within a range of 12 to $15 \mathrm{~mm} \mathrm{Hg}$ ). None of the patients had angle abnormalities or glaucomatous changes in the optic nerve. The patient's other 2 daughters and 2 other grandchildren were unaffected.

All the affected family members underwent an ultrabiomicroscopic examination which clearly revealed a pupil diameter of $1.8 \mathrm{~mm}$ and an iris thickness of $830 \mu$, confirming the CMC diagnosis, with no angle findings (fig. 2c). A scan of patient 1 showed an axial length of $26 \mathrm{~mm}$ and an intraocular lens (IOL) predicted power for emmetropia of +14.00 . After retrobulbar block, phacoemulsification with implantation of an acrylic IOL and pupillary margin biopsy and reconstruction were performed in both eyes. Clinically, the lens anterior capsule that was removed during the capsulorhexis appeared to be of normal consistency and thickness.

\section{Results}

The postoperative recovery was uneventful; 1 day postoperatively the uncorrected Snellen visual acuity was 20/25 in both eyes. At 1 month, the pupil was $5 \mathrm{~mm}$ in size, with still no response to mydriatics (fig. 1c, d). The histopathological examination of the removed pupillary margin revealed smooth sphincter muscle fibers, fusiform and dendritic melanocytes and pigmentary epithelium cells, and the iris stroma showed fusiform and dendritic melanocytes, a few blood vessels and no smooth muscle cells (fig. $\underline{3}$ a, b). Application of Masson's trichrome histochemical stain showed melanocytes in the iris anterior stroma, smooth muscle fibers, connective tissue, and pigmentary epithelium (fig. 3c).The removed lens capsule was stained with periodic acid-Schiff (PAS) which 
revealed regular thickness base membrane and cuboidal epithelial cells underneath (fig. 3d).

\section{Discussion}

Inherited CMC, also called congenital miosis (MCOR; OMIM 156600), is an uncommon anterior segment anomaly caused by a defect of intermediate filaments in the terminal fetal stages of differentiation of the anterior pigmented epithelial cell of the iris. This results in the absence of myofilaments and consequent failure of development of a functional dilator pupil muscle, with the predominance of sphincter muscle function, creating a static pupil diameter of less than $2 \mathrm{~mm}$ with the collarette displaced towards the pupil, peripheral iris hypopigmentation and transillumination defects. Affected individuals do not have light or accommodations reflexes and have no response to topically administered mydriatic drugs [1].

$\mathrm{CMC}$ is associated with juvenile open angle glaucoma and myopia due to an increased mean axial length of the eye, with a positive coefficient of correlation between age and axial length of the eye [3-5]. We found this association in our patients, since the 9-yearold grandson was emmetropic, the 41-year-old son had a -7.00 myopic refractive error, and the eldest affected member had an IOL predicted power of +14.00 . However, in our cases, there was no evidence of glaucoma in any of the affected and non-affected individuals. We will follow as closely as possible the young subjects to evaluate whether they will develop late-onset congenital glaucoma [4]. Pinhole pupils cause a decrease in light sensitivity which is approximately proportional to the reduction of the area of the pupillary aperture; therefore, nyctalopia is common in patients with CMC [6], as we report in our patients. Linkage analysis in French and Indian pedigrees indicated that the responsible gene is located in the chromosomal locus 13q31-q32, but up to date, no responsible gene has been identified; however, the transmission is autosomal dominant $[2,7]$. Some ocular, neurological or kidney associations have been reported such as goniodysgenesis [8], ataxia [9] or nephrosis [10], respectively, but none of those were present in our patients. They usually require optical correction only, but visual acuity deteriorates with a subtle nuclear sclerosis, and may need surgical treatment, with different approaches described, including cataract surgery and optical iridectomy to improve the symptoms [6]. We preferred to perform a pupilloplasty in order to keep a more natural looking pupil, achieving great results and avoiding iridectomy-related photophobia.

Histopathological examinations of the pupillary border confirmed that the iris is thinner, richer in cells and ground substance and has an incompletely developed dilator muscle. However, apart from the stroma, the innervation, vasculature and cellular relationships are no different from those in a normal iris, as reported previously [11]. The examination of the excised anterior lens capsule showed no base membrane alterations, therefore, the developmental anomaly is present just in the iris. The ultrasound biomicroscopy could be a great option to confirm the disorder when the affected individuals do not need surgery, since iris thickness is a great feature of this anomaly.

To our knowledge, this is the first ultrabiomicroscopic analysis in a family with autosomal dominant CMC in Latin America. Although CMC is uncommon, genetic molecular studies may be appropriate in this familial case to identify a causal gene. 


\section{Disclosure Statement}

No author has a financial or proprietary interest in any material or method mentioned.

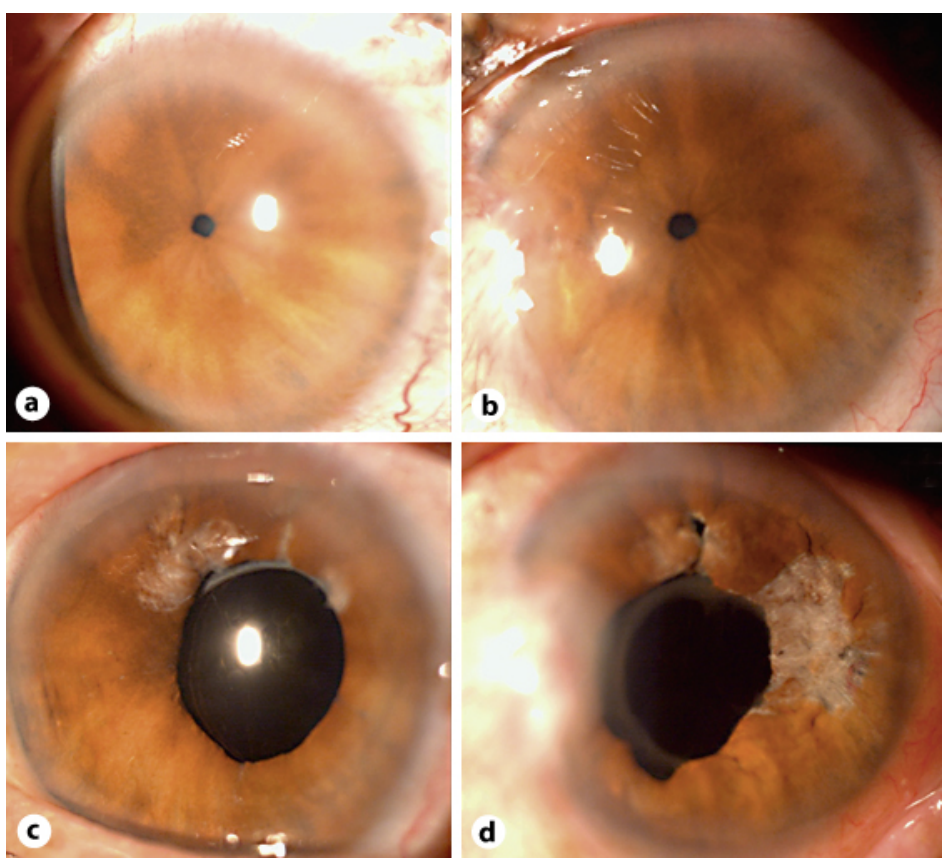

Fig. 1. Patient 1 with pupils of less than $2 \mathrm{~mm}$ in scotopic illumination, with a hyperpigmented peripupillary area (a right eye; $\mathbf{b}$ left eye). After surgery, the pupils were $5 \mathrm{~mm}$ in size (c right eye; $\mathbf{d}$ left eye).
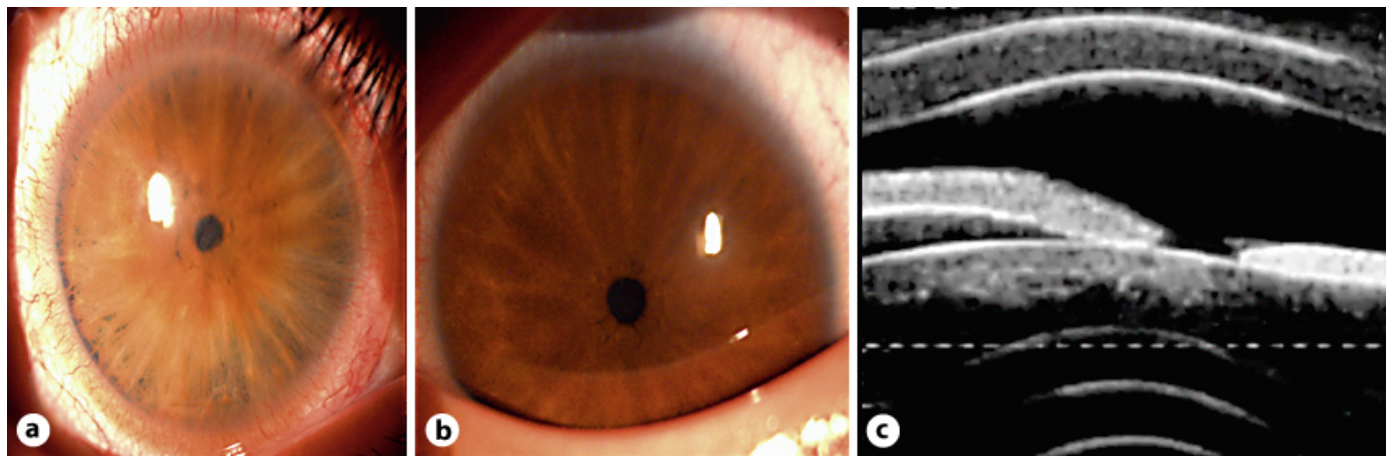

Fig. 2. a Right eye of the 41-year-old son (patient 2). b Right eye of the 9-year-old grandson (patient 3). c $50-\mathrm{MHz}$ ultrabiomicroscopy showing iris diameter of less than $1.8 \mathrm{~mm}$ and iris thickness of less than $830 \mu$. 

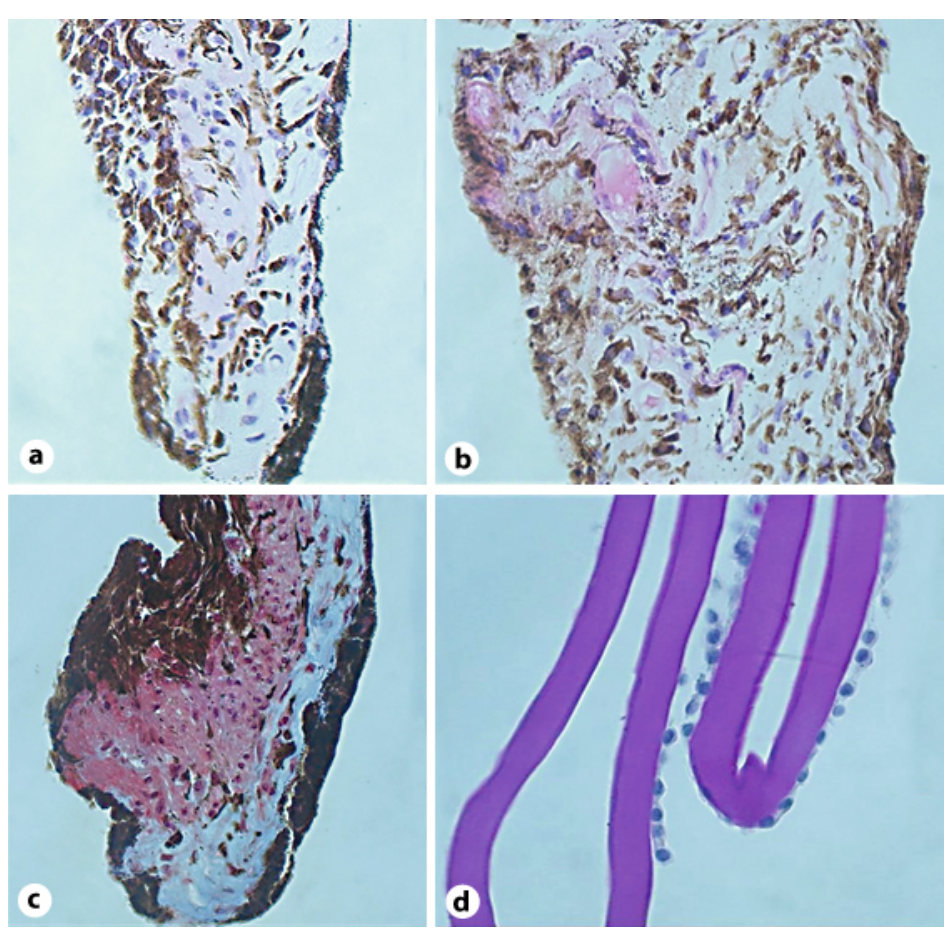

Fig. 3. a Histological section of pupillary border showing fusiform and dendritic melanocytes, a few blood vessels, and no smooth muscle cell capsules and an underlying pigmentary epithelial layer (H\&E stain). b Histological section of iris middle stroma with a few smooth muscle fibers and a thin appearance. c Masson's trichrome stain showing melanocytes in the iris anterior stroma, smooth muscle fibers, connective tissue and pigmentary epithelium. d PAS stain of the anterior lens capsule showing regular thickness base membrane and cuboidal epithelial cells underneath. 


\section{References}

$\checkmark 1$ Pietropaolo A, Corvino C, DeBlasi A, Calabrò F: Congenital microcoria: case report and histological study. J Pediatr Ophthalmol Strabismus 1998;35:125-127.

-2 Ramprasad VL, Sripriya S, Ronnie G, Nancarrow D, Saxena S, Hemamalini A, Kumar D, Vijaya L, Kumaramanickavel G: Genetic homogeneity for inherited congenital microcoria loci in an Asian Indian pedigree. Mol Vis 2005;11:934-940.

-3 Toulemont PJ, Urvoy M, Coscas G, Lecallonnec A, Cuvilliers AF: Association of congenital microcoria with myopia and glaucoma. A study of 23 patients with congenital microcoria. Ophthalmology 1995;102:193-198.

-4 Tawara A, Itou K, Kubota T, Harada Y, Tou N, Hirose N: Congenital microcoria associated with late-onset developmental glaucoma. J Glaucoma 2005;14:409-413.

5 Saxena S, Saxena RC: Congenital microcoria: A study in three generations. Indian J Ophthalmol 1993;41:130132.

6 Meire FM, Delleman JW: Autosomal dominant congenital miosis with megalocornea. Ophthalmic Paediatr Genet 1992;13:123-129.

7 Rouillac C, Roche O, Marchant D, Bachner L, Kobetz A, Toulemont PJ, Orssaud C, Urvoy M, Odent S, Le Marec B, Abitbol M, Dufier JL: Mapping of a congenital microcoria locus to 13q31-q32. Am J Hum Genet 1998;62:1117-1122.

-8 Mazzeo V, Gaiba G, Rossi A: Hereditary cases of congenital microcoria and goniodysgenesis. Ophthalmic Paediatr Genet 1986;7:121-125.

9 Dick DJ, Newman PK, Cleland PG: Hereditary spastic ataxia with congenital miosis: four cases in one family. Br J Ophthalmol 1983;67:97-101.

10 Bredrup C, Matejas V, Barrow M, Bláhová K, Bockenhauer D, Fowler DJ, Gregson RM, Maruniak-Chudek I, Medeira A, Mendonça EL, Kagan M, Koenig J, Krastel H, Kroes HY, Saggar A, Sawyer T, Schittkowski M, Swietliński J, Thompson D, VanDeVoorde RG, Wittebol-Post D, Woodruff G, Zurowska A, Hennekam RC, Zenker M, Russell-Eggitt I: Ophthalmological aspects of Pierson syndrome. Am J Ophthalmol 2008;146:602611 .

11 Butler JM, Raviola G, Miller CD, Friedmann AI: Fine structural defects in a case of congenital microcoria. Graefes Arch Clin Exp Ophthalmol 1989;227:88-94.

Presented in part at the ARVO meeting, Fort Lauderdale, Fla., USA, May 2010. Presented as a video at the ESCRS meeting, Paris, France, September 2010, and at the AAO meeting, Chicago, Ill., USA, October 2010. 